\title{
OPTIMIZING THE BEHAVIOR OF THE EMERGING ADULT BY DECREASING OF MALADAPTIVE MENTAL SCHEMAS
}

\author{
Violeta Lungu ${ }^{1}$, Mihaela Stomff ${ }^{2}$
}

\begin{abstract}
The article presents the research results on the effects of a program for optimizing emerging adults' behavior in Romania. Behavior optimization was achieved by improving maladaptive mental schemas through group cognitive-behavioral interventions. The research was conducted in two stages. The research's initial stage consisted of an investigation of a group of 212 young people (19-30 years old) belonging to the NEET category (Not in Education, Employment, or Training). The psychological tools assessed the personality, the level of manifestation of cognitive and emotional maladaptive schemas, Personal Autonomy, and Self Efficacy. The second stage of the research involved 48 NEET young people who participated in a personal development program to optimize behavior for a period of 18 months. Participants experienced improvements in dysfunctional mental schemas, reported increases in personal autonomy and flexibility, and adaptive changes in personality structure. This research is a first in Romania and joins the efforts to improve the psycho-social condition of young NEETs in Romania (currently at $16.8 \%$ ).
\end{abstract}

UDC Classification: 159.92, DOI: https://doi.org/10.12955/pss.v2.227

Keywords: emerging adults, NEET, cognitive schemas, autonomy, self-efficacy

\section{Introduction}

The concept of emerging maturity describes the period of development between 18 and 30 years (Arnett, 2014). In the 2000s, J. Arnet studied this age group (called „millennials” at the time) and concluded that the tasks of development at this stage of life are: leaving the parents' home, completing education, finding a job, developing a stable relationship or marriage, starting a family, reconfiguring and reframing relationships with parents on other bases, shaping and building the foundations of a career, moral development/belief system, vision and hope regarding the future.

J. Arnett's research has concluded that the traditional markers of maturity have changed, becoming accepting of responsibility for oneself, the ability to make decisions independently, and financial independence. J. Arnett considers this paradigm shift to be the result of major changes in the western world in the 1960s and 1970s (the technological revolution, the sexual revolution, the feminist, and youth movement). Eastern Europe aligned itself with these societal changes after the revolutions of the late 1990s. As a result of the radical changes in society that have diminished the social pressure, it has been found that young people are late in maturing, they extend their studies, get married later and experience prolonged transitions to adulthood. The significant extension of the maturity period has generated new characteristics and tasks for the emerging adult: a. the exploration of identity, which seeks an answer to the question "who am I?" and trying different options, especially in the sentimental and professional sphere - reason for which the period is characterized by instability; b. self-centeredness, given the limited nature of obligations toward others; $c$. the feeling of being in transition, the in-between age, neither adolescent nor adult; d. possibilities and optimism, the period when people feel that they have their whole life ahead and can build their life the way they want.

Within this category of people who are in the third decade of life in the terms described by J. Arnett, there is a subcategory of young people, whose number is growing and who have received the NEET label - an acronym for Not in Education, Employment, or Training, refers to a person who is unemployed and not receiving an education or vocational training. In the present study, disadvantaged socioeconomic environments were not investigated. Access to education and work is limited. Social exclusion, instability, and vulnerability are generated by objective causes, as in economically and socially disadvantaged areas. In this study, we were concerned with the psychological aspects of young NEETs who live in a large city, such as the capital of Romania, Bucharest, and come from middle-class families at a socio-economic and educational level. Also, young people who cannot find a job or continue their studies due to health/disability reasons are not discussed. The study was attended by healthy young people, high school graduates, who benefit from the extension of parenting practices in terms of age beyond adulthood. The study's hypothesis assumed the existence of maladaptive mental schemas that slow down the progress of development tasks in the new paradigm proposed by J. Arnett.

\footnotetext{
${ }^{1}$ Ion Creangă State Pedagogical University, Doctoral School Of Psychology, Chișinău, Moldova, violeta.lungu@gmail.com, ORCID: 0000-0002-4574-2089

${ }^{2}$ Ion Creangă State Pedagogical University, Doctoral School Of Psychology, Chișinău, Moldova, stomff@yahoo.com
} 
We considered that the development of the personality of these young people could result in a delayed process of starting in life, some of them never tried, while some others abandoned due to failures, which strengthened the manifestation of early maladaptive schemas (e.g., failure, vulnerability, punishment, etc.). In the initial phase of the present research, we confirmed that the levels of manifestation of the areas of maladaptive schemas were higher than in young people who do not belong to the NEET category. We also considered autonomy and self-efficacy as psychological risk factors to enter the NEET category.

\section{NEET young people - behavioral development and optimization}

For young NEETs, optimizing behavior could mean balancing the needs for autonomy, competence, relationships, security, and self-concept; identifying objectives that meet these needs and that match their own talents and aspirations; identifying self-regulation and adaptive coping strategies; identifying personal strengths and cultivating them; constant capacity for self-evaluation and implicitly the change of personal objectives when the conditions impose it. In other words, to be an optimal being, in a humanistic sense, means to work constantly to become the person that everyone is capable of being. These competencies would be autonomy, self-determination, self-efficacy, resilience, flexibility, internal attribution of responsibility, concordance, and coherence of the objectives with the motivational needs. In a study, Sheldon and Kasser (2001) started from the premise that self-concordance of goals, i.e., the consistency of a person's interests with their core values, is more likely to achieve goals and reap the benefits of achieving these goals. The effects of personal well-being are mediated by the satisfaction of the needs of autonomy, competence, and activity-based relationships. They accumulate during periods of effort to achieve these self-consistent goals. Objectives are cognitive structures characterized by uniqueness, invested with motivational energy, and functional autonomy. Objectives, in order to bring well-being to the person, must be in line with genuine values and interests based on themselves. Otherwise, the energy efforts required to achieve these goals can be painful? Carl Rogers believed that individuals possessed the necessary mechanisms to assess the self-agreement of objectives. The proposed psychological intervention program aimed at optimizing adaptive behavior by improving dysfunctional mental schemas (Young, Klosko, \& Weishaar, 2003), increasing personal autonomy, and a sense of self-efficacy.

\section{Research design}

A simple randomized controlled study was used to evaluate the effects of psychological intervention on the domains of early maladaptive schemas, autonomy, and personal efficiency. The design of the study involved two stages. The first stage of finding out the particularities of young NEETs. The initial research sample consisted of 212 people (100 f, i.e., $47.2 \%$ and $112 \mathrm{~m}$, i.e., $52.8 \%$ ) aged between 19 and 30 years. The average age is 24.33 years. The first stage of research aimed at identifying the differences between young NEETs and non-NEETs. Professional status: 41 employees (19\%), 84 students (40\%), 43 (20\%) without occupation, $44(21 \%)$ employed students. In the second stage, NEET young people were selected for the intervention (plus students enrolled in the second or third faculty, without finishing the first one).

We identified that NEET young people have higher levels of early maladaptation schemas, lower personal autonomy, and self-efficacy than non-NEET young people. In the second stage of the research, we evaluated a psychological intervention to reduce maladaptive patterns and increase personal autonomy and self-efficacy.

\section{Research participants}

The research involved 48 young people aged between 23 and 26 years. The procedure used to select the participants was performed in two stages. In the first stage, 212 young people were recruited who participated in the initial finding study. The eligibility conditions were as follows: (1) has never worked or has had only temporary/seasonal jobs with a duration of less than three months in a row, (2) has no completed university studies, (3) is not in training or education, (4) lives with and is maintained by parents, (5) does not have a special medical condition - physically and/or mentally. From the initial group, 48 young people were selected, randomly assigned to the experimental and control groups.

\section{Procedure}

The intervention program was based on the principles stated by Yalom and Leszcz (2008) for personal growth-development-healing groups. The methods and techniques belonged to the cognitive-behavioral 
approaches, given that they represent the body of guidelines with the widest basis of scientifically proven effectiveness (e.g., Dobson and Dobson, 2018): The Cognitive Behavioral Model (A.T. Beck), The Rational Emotional and Behavioral Model focused on solving emotional and behavioral problems (Ellis and Maclaren, 2018), The Dysfunctional Metacognitive Beliefs model (Wells and Cartwright-Hatton, 2004), The Early Maladaptive Schemas Model (Young, Klosko and Weishaar, 2003), The Emotional Schema Model (Leahy, 2019), The Solution-Focused Therapy Model (by Shazer et al., 2007; Macdonald, 2011), The Psychological Flexibility Model - ACT (Hayes and Strosahl, 2005), elements of philosophical counseling (Marinoff, 2001; Cohen, 2007), Neuro-linguistic programming techniques (Dilts et al., 1980). The principles of the psychological intervention program were: positive orientation on strengths (Pittman et al., 2002), universality or inclusion (Hamilton, Hamilton, and Pittman, 2004), acceptance of the process, respect for the principles of humanistic theories of personal growth and development, individual performance optimization through progressive personal development, balancing the personality system by being aware of what is realistic, achievable and personally relevant, respect for personal choices and interpretation of personal experiences. The characteristics of the program involved: identification of personal SMART objectives (Specific, Measurable, Achievable, Realistic and Time-bounded); encouraging personal reflection on situational processes according to the principle that long-term personality development takes place due to repeated short-term situational processes (Wrzus and Roberts, 2016) and specific feedback as part of the development of communication and interrelationship skills.

The program lasted 18 months, with the frequency of 1 session two days a month (weekend). Each session lasted 16 hours (8 hours per day).

Measures

Early maladaptive schemas were assessed with The Young Schema Questionnaire - Short form 3 (YSQS3). The questionnaire has 114 items that evaluate 16 cognitive schemes organized in five main areas (Young and Brown, 1994):

I. Disconnection-Rejection includes five schemas: Abandonment/Instability, Mistrust/Abuse, Emotional Deprivation, Defectiveness/Shame, and Social Isolation/Alienation. It describes feelings of disappointment/frustration experienced in relation to expectations of personal security, stability, affection, empathy, sharing feelings, acceptance, and respect.

II. Impaired Autonomy and/or Performance includes 4 schemas: Dependence/Incompetence, Vulnerability to Harm or Illness, Failure, Enmeshment/Undeveloped Self. It describes disabling feelings that result from a person's beliefs that personal autonomy and confidence are diminished.

III. Impaired Limits include two schemas: Entitlement/Grandiosity and Insufficient Self-Control and/or Self-Discipline. It expresses difficulties in respecting social norms and the rights of others and common goals and objectives.

IV. Other-Directedness includes three schemas: Subjugation, Self-Sacrifice, and ApprovalSeeking/Recognition-Seeking. It expresses focus on the needs of others in order to gain affection and approval.

V. Over Vigilance/Inhibition includes four schemas: Negativity/Pessimism, Emotional Inhibition, Unrelenting Standards/Hyper criticalness, Punitiveness. Schemas in this area block spontaneity, free self-expression, relaxation. The person has strict rules and expectations regarding performance and ethical behavior.

Personal autonomy was investigated with a Romanian tool that evaluates four dimensions of autonomy: cognitive autonomy, behavioral autonomy, emotional autonomy, value autonomy, and a global score. We work with the global score because the authors of the instrument briefly defined personal autonomy as the ability of the individual to control its own life together with the feeling that there is the possibility to exercise this control (Berar și Albu, 2006).

Personal self-efficacy was investigated with the General Self-Efficacy Scale (GSE, Schwarzer, 1995). It contains 10 items that measure the self-efficacy defined as the person's confidence in their own abilities, especially in facing challenges and completing a task. It differs from specific self-efficacy (academic, sports, parenting, etc.), self-esteem, self-regulation, and motivation. 
In addition to the results measured with quantitative psychometric instruments, the development of the intervention allowed secondary qualitative research on group dynamics, according to the model of Tuckman (1984).

Data analysis was performed with SPSS Statistics 26 (SPSS Inc., Chicago, IL, USA) and JASP Version 0.14.1 (JASP Team, 2020).

\section{Results}

The experimental group and the control group were homogeneous (demographic characteristics and pretest results). Table 1 shows the mean and standard deviations in the pretest, where the significance test for GE (the experimental group) and GC (the control group) in the pretest was insignificant for all investigated dimensions.

The effects of the psychological intervention program on early schemas, autonomy, and self-efficacy

The T-test for independent samples was used to assess the effects of psychological intervention on early maladaptive mental schemas, personal autonomy, and self-efficacy (Table 1). In the posttest, participants in the experimental group compared to those in the control group reported significantly lower scores for the areas of early maladaptive conditions and significantly higher scores on Autonomy and Self-efficacy $(\mathrm{p}<.05)$. These significant values represented dimensions with moderate and high effect, between \pm 0.69 and \pm 0.88 ).

Table 1: Comparison of variables outcomes between experimental group and control group

\begin{tabular}{|c|c|c|c|c|c|c|c|c|c|}
\hline \multirow[b]{2}{*}{ Variables } & \multicolumn{4}{|c|}{ Experimental group $(\mathrm{N}=24)$} & \multicolumn{3}{|c|}{ Control Group ( $\mathrm{N}=24)$} & \multirow{2}{*}{$\overline{\mathrm{P}}$} & \multirow{2}{*}{$\begin{array}{l}\text { Effect } \\
\text { Cohen d }\end{array}$} \\
\hline & $\begin{array}{l}\text { Mean } \\
(\mathrm{SD})\end{array}$ & $\begin{array}{l}\text { Mean } \\
(\mathrm{SD})\end{array}$ & $\mathrm{T}$ & $\mathrm{p}$ & $\begin{array}{l}\text { Mean } \\
\text { (SD) }\end{array}$ & $\begin{array}{l}\text { Mean } \\
\text { (SD) }\end{array}$ & $\mathrm{t}$ & & \\
\hline & pretest & posttest & & & pretest & posttest & & & \\
\hline Self-efficacy & $\begin{array}{l}22.1 \\
(4.7)\end{array}$ & $\begin{array}{l}28.5 \\
(6.1)\end{array}$ & -4.772 & .001 & $\begin{array}{l}23.2 \\
(5.2)\end{array}$ & $\begin{array}{l}23.3 \\
(6.9)\end{array}$ & -.104 & .692 & $\mathrm{~d}=.799$ \\
\hline Autonomy & $\begin{array}{l}61.1 \\
(10.2)\end{array}$ & $\begin{array}{l}74.5 \\
(13.8)\end{array}$ & -8.149 & .002 & $\begin{array}{l}64.3 \\
(12.1)\end{array}$ & $\begin{array}{l}65.2 \\
(12.9)\end{array}$ & -.149 & .552 & $\mathrm{~d}=.696$ \\
\hline $\begin{array}{l}\text { I. Disconnection } \\
\text {-Rejection }\end{array}$ & $\begin{array}{l}46.2 \\
(16.8)\end{array}$ & $\begin{array}{l}35.3 \\
(15.1)\end{array}$ & -2.479 & .001 & $\begin{array}{l}48.7 \\
(18.8)\end{array}$ & $\begin{array}{l}46.3 \\
(16.1)\end{array}$ & -1.24 & .438 & $\mathrm{~d}=.705$ \\
\hline $\begin{array}{l}\text { II. Impaired } \\
\text { Autonomy and/or } \\
\text { Performance }\end{array}$ & $\begin{array}{l}46.5 \\
(16.2)\end{array}$ & $\begin{array}{l}35.6 \\
(16.1)\end{array}$ & -6.961 & .001 & $\begin{array}{l}48.9 \\
(17.3)\end{array}$ & $\begin{array}{l}49.2 \\
(15.4)\end{array}$ & -.938 & .368 & $d=.863$ \\
\hline III. Impaired Limits & $\begin{array}{l}22.6 \\
(7.7)\end{array}$ & $\begin{array}{l}16.9 \\
(8.6)\end{array}$ & -5.993 & .003 & $\begin{array}{l}24.5 \\
(7.4)\end{array}$ & $\begin{array}{l}23.4 \\
(7.8)\end{array}$ & .432 & .674 & $\mathrm{~d}=.792$ \\
\hline $\begin{array}{l}\text { IV. Other- } \\
\text { Directedness }\end{array}$ & $\begin{array}{l}38.2 \\
(7.1)\end{array}$ & $\begin{array}{l}28.2 \\
(8.2)\end{array}$ & -3.586 & .002 & $\begin{array}{l}38.4 \\
(6.6)\end{array}$ & $\begin{array}{l}36.2 \\
(9.8)\end{array}$ & 1.037 & .831 & $\mathrm{~d}=.885$ \\
\hline $\begin{array}{l}\text { V. Over vigilance - } \\
\text { Inhibition }\end{array}$ & $\begin{array}{l}24.3 \\
(4.3)\end{array}$ & $\begin{array}{l}18.9 \\
(7.3)\end{array}$ & -6.509 & .005 & $\begin{array}{l}25.2 \\
(3.9)\end{array}$ & $\begin{array}{l}24.1 \\
(6.5)\end{array}$ & .293 & .786 & $\mathrm{~d}=.752$ \\
\hline
\end{tabular}

\section{Discussion}

This study evaluated the effect of a psychological program on maladaptive mental schemas, personal autonomy, and self-efficacy in young NEETs in randomized controlled trials. The psychological intervention program improved the level of manifestation of the areas of early maladaptive schemas and increased the level of autonomy and perception of personal self-efficacy. Therefore, the principles of personal development and support groups, together with the methods and techniques of cognitivebehavioral interventions, can be used to optimize the behavior of young NEETs. We started from the premise that the impasse of NEET youth, namely the diminished ability to perform emerging adult tasks (according to J. Arnett's theory), is caused by the manifestation of early maladaptive schemas and selfperception of autonomy and diminished self-efficacy.

This article presents the results of the experimental-formative stage, in which only young NEETs participated, constituted in an experimental group (GE) and a control group (GC). The results confirmed the effectiveness of group interventions and cognitive-behavioral methods and techniques, and positive psychology (e.g., Boiler et al., 2013).

Studies have shown that autonomy and independence are important values at the age of emerging maturity, linked to autonomous self-development. Increased levels of autonomy were positively related to exploratory behavior and flexible engagement but negatively related to avoidance behaviors. The results suggest that one of the main tasks of emerging maturity is the consonantal orientation and 
coherence of identity in relation to the degree of autonomy (Arnett, 2014). The period between 20 and 26 years seems to be the most appropriate for the implementation of support programs to prevent the consequences of poor perception of self-efficacy. Self-efficacy is also related to self-personal coherence (Stomff and Vasiliu, 2017). According to the Big Five model, decreasing early maladaptive schemas can improve personality factors (e.g., Sava, 2009; Thimm, 2010; Lungu and Stomff, 2017).

\section{Conclusion}

These results demonstrate an improved outcome of the participants in the psychological intervention group. The intervention facilitated the psychological development and behavioral optimization for NEET young people, which aims to hire, resume and complete studies, reduce parental dependence, helping young NEETs to overcome this condition, to continue their starting path in life.

\section{References}

Arnett, J.J. (2014). Emerging Adulthood: The Winding Road from the Late Teens Through the Twenties, Second Edition. Oxford University Press.

Berar, I., Albu, M. (2006b). Un chestionar pentru evaluarea autonomiei personale la adolescenți. În: Studii și cercetãri din domeniul științelor socio-umane, vol. 15, pp. 30-41. Cluj-Napoca: Editura Argonaut

Boiler, L., Haverman, M., Westerhof, G., Riper, H., Smit, F., Bohlmeijer, E. (2013). Positive psychology interventions: a meta-analysis of randomized controlled studies. BMC Public Health, 13, 119. https://doi.org/10.1186/1471-2458-13-119

Cohen, E. (2006). The New Rational Therapy: Thinking Your Way to Serenity, Success, and Profound Happiness. Rowman \& Littlefield Publishers, Inc. ISBN-10: 0742547345, 310 p.;

de Shazer, S., Dolan, Y., Korman, H., McCollum, E., Trepper, T., Berg, I. K. (2007). More than miracles: The state of the art of solution-focused brief therapy. Haworth Press;

Dilts, R., Grinder, J., Delozier, J., and Bandler, R. (1980). Neuro-Linguistic Programming: Volume I: The Study of the Structure of Subjective Experience. Cupertino, CA: Meta Publications. ISBN 978-0916990077. 284 p.

Dobson, D., Dobson, K. (2018). Evidence-Based Practice of Cognitive-Behavioral Therapy (2nd Edition). Guilford.com eBooks. ISBN $9781462538027,354 \mathrm{p}$.

Hamilton, S.F., Hamilton, M.A., Pittman, K. (2004). Principles for Youth Development. In S.F. Hamilton \& M.A. Hamilton (Eds.) The Youth Development Handbook: Coming of Age in American Communities (pp.3-22). Thousand Oaks: Sage Publications, Inc.;

Hayes, S. C., Strosahl, K. D. (2005) (Eds.). A practical guide to Acceptance and Commitment Therapy. New York: SpringerVerlag. eBook ISBN 978-0-387-23369-7. 396 p.;

JASP Team (2020). JASP (Version 0.14.1)[Computer software].

Leahy, R. (2019) Introduction: Emotional Schemas and Emotional Schema Therapy. International Journal of Cognitive Therapy, vol. 12, pp. 1-4;

Lungu, V., Stomff, M. (2017). The Early Maladaptive Cognitive Schemas and Personality Traits in Emerging Adulthood, pp. 424-437. 10.18662/lumproc.rsacvp2017.39;

Macdonald, A. (2011). Solution-focused therapy: Theory, research and practice (2nd ed.). London: Sage Publications, Ltd. ISBN-13: 978-1412931168, ISBN-10: 1412931169;

Marinoff, L. (2001). Philosophical Practice. Academic Press (1st edition). ISBN-10: 9780124715554,411 p.;

Pittman, K., Irby, M., Tolman, J., Yohalem, N., Ferber, T. (2002). Preventing problems, promoting development, encouraging engagement: Competing priorities or inseparable goals? Washington, DC: Forum for Youth Investment;

Sava, F. (2009). Maladaptive schemas, irrational beliefs, and their relationship with the five-factor personality model. Journal of Cognitive and Behavioral Psychotherapies, vol. 9(2), pp. 135-147;

Sheldon, K., Kasser, T. (2001). Goals, Congruence, and Positive Well-Being: New Empirical Support for Humanistic Theories. Journal of Humanistic Psychology, vol. 41 (1), pp. 30-50

Schwarzer, R., Jerusalem, M. (1995). Generalized Self-Efficacy scale. In J. Weinman, S. Wright, \& M. Johnston, Measures in health psychology: A user's portfolio. Causal and control beliefs (pp. 35-37). Windsor, UK: NFER-NELSON.

Stomff, M., Vasiliu, D. (2017). The Self-Efficacy of the Emerging Adult, Student or Graduate. In C. Ignatescu, A. Sandu, T. Ciulei (eds.), Rethinking Social Action. Core Values in Practice (pp. 855-863). Suceava, Romania: LUMEN Proceedings https://doi.org/10.18662/lumproc.rsacvp2017.78

Thimm, J. (2010). Personality and early maladaptive schemas: A five-factor model perspective. Journal of Behaviour Therapy and Experimental Psychiatry, vol. 41, pp. 373-380;

Tuckman, B. W., Jensen, M. A. (1977). Stages of small-group development revisited. Group \& Organization Studies, vol. 2(4), pp. 419-427;

Young, J., Brown, G. (1994). Young Schemas Questionnaire - S1. New York, NY: Cognitive Therapy Center;

Young, J., Klosko, J.S., Weishaar, M.E. (2003). Schema therapy. A practitioner's guide. New York: Guilford Press.

Wells, A., Cartwright-Hatton, S. (2004). A short form of the metacognitions questionnaire: Properties of the MCQ-30. Behaviour Research and Therapy, vol. 42, pp. 385-396

Wrzus, C., Roberts, B. (2016) Processes of Personality Development in Adulthood: The TESSERA Framework. Personality and Social Psychology Review, vol. 21 (3). doi:10.1177/1088868316652279 